\title{
$\begin{array}{ll}\text { Research Square } & \text { Theprints are preliminary reports that have not undergone peer review. } \\ \text { Theuld not be considered conclusive, used to inform clinical practice, }\end{array}$ or referenced by the media as validated information. \\ Can Environmental Regulation Promote Domestic Market Integration? Evidence From China
}

\section{Aolin Lai}

Anhui University of Finance and Economics

\section{Zhihui Yang ( $\nabla$ zhi-hui-yang@163.com )}

Anhui University of Finance and Economics https://orcid.org/0000-0002-5086-7791

\section{Lianbiao Cui}

Anhui University of Finance and Economics

\section{Research Article}

Keywords: environmental regulation, market segmentation, fiscal decentralization, spatial effect

Posted Date: June 14th, 2021

DOl: https://doi.org/10.21203/rs.3.rs-551740/v1

License: (1) This work is licensed under a Creative Commons Attribution 4.0 International License. Read Full License 


\section{Evidence from China}

3

$4 \quad$ Aolin Lai ${ }^{\mathrm{a}}$, Zhihui Yang ${ }^{\mathrm{a}^{*}}$, Liaobiao Cui ${ }^{\mathrm{a}}$

5

6 a School of Statistics and Applied Mathematics, Anhui University of Finance and Economics,

7 Bengbu, Anhui 233030, PR China

8

9 *Corresponding Author. E-mail: zhi-hui-yang@163.com (Z. Yang)

10 Tel: +8613909653010

11 Fax: 0552-3169051

12

First Author (A. Lai). E-mail: 1aiaolin@163.com

14

Third author (L. Cui). E-mail: cuilb1987@126.com

16

\section{Acknowledgements}

This work was supported by the National Natural Science Foundation of China [grant no. 71974001], the Major Research Projects of Natural Science in Universities of Anhui Province of

20 China [grant no. KJ2017ZD35], and the Top Talent Project in Anhui Province [grant no. 21 gxyqZD2020087]. We would like to thank Editage (www.editage.cn) for English-language editing. 


\title{
Can environmental regulation promote domestic market integration?
}

Evidence from China

\author{
Aolin Lai Zhihui Yang ${ }^{1} \quad$ Lianbiao Cui \\ School of Statistics and Applied Mathematics, Anhui University of Finance and Economics, \\ Bengbu, Anhui 233030, PR China
}

\begin{abstract}
While local protectionism and market segmentation owing to fiscal decentralization are not conducive to broad economic development, they may be rational choices on a local scale. Based on a spatial Durbin model, we analyzed the relationship between environmental regulations and market segmentation in China using interprovincial panel data for 2004-2018. The results indicated that the "beggar-thy-neighbor" phenomenon persists in China; environmental regulations have a Ushaped impact on market segmentation, i.e., in most regions, environmental regulations strongly promote local market integration. Regions with greater decentralization are better able to promote local market integration through environmental regulation, suggesting that local governments are better able to compensate for market failures when vested with greater power. Hence, we propose that the central government should improve performance evaluation indicators for local governments and grant them greater autonomy; additionally, local governments should increase the intensity of environmental regulations as appropriate, thereby promoting both environmental protection and the unification of domestic markets.
\end{abstract}

Keywords: environmental regulation; market segmentation; fiscal decentralization; spatial effect

\section{Introduction}

Since the reform and opening up, China has achieved tremendous economic growth owing to its market-oriented reforms, particularly that of permitting the market to play a critical role in allocating resources (Cui et al. 2019; Duan et al. 2019). History has indicated that rapid economic development depends on efficient free markets, which thrive under integrated rather than fragmented or isolated conditions (Jin et al. 2008; Lai et al. 2021). The unification of the domestic market promotes competition, the development and application of new technologies, and the gradual standardization of market rules, thus realizing the optimal allocation of resources. Therefore, reducing market segmentation in favor of domestic integration, accelerating the establishment of a competitive, orderly, unified, and open free-market system, and allowing the market mechanism to play the decisive role in resource allocation have become important practical issues for the development of China's market economy.

\footnotetext{
${ }^{1}$ Corresponding Author: zhi-hui-yang@163.com
} 
Since fiscal decentralization, the Chinese market has existed in a fragmented state. Market segmentation can be measured via production (Young 2000), trade law (Poncet 2003), and relative price (Parsley and Wei 1996) methods, which scholars have applied to conduct preliminary assessments of market segmentation in China. Although some controversy exists regarding the trend of market segmentation in China, economists generally agree that market segmentation is a major problem. Segmentation reduces market efficiency and slows technological progress, which is detrimental to both economic development and environmental protection ( $\mathrm{Li}$ and $\mathrm{Lu}$ 2020; Sun et al. 2020; Zhang et al. 2020; Zhu et al. 2020). Initial research on the causes of market fragmentation in China has focused on local protectionism, which is generally considered a primary cause of market fragmentation and is motivated by strong profit-based motives. Fiscal decentralization is also a manifestation of local protectionism (Fan and Zhang 2010; Song et al. 2020). Fiscal decentralization enables local governments to obtain a more reasonable distribution of financial and administrative power; however, it can lead to self-promotion by local officials and the implementation of "catch-up" strategies to more rapidly secure economic benefits, thereby leading to over-intervention by the government and preventing market integration.

Domestic market integration is typically a gradual process, and market segmentation is not unique to periods of economic transition. While the factors that lead to market segmentation are diverse, they can be broadly categorized into institutional (Li et al. 2003; Xiwei et al. 2005), geographic (Fan et al. 2017), and market factors. Institutional factors include local protectionism stemming from political, economic, and other factors; geographic factors refer to the segmentation of two markets due to differences in initial resource endowment and geographic location. Finally, market factors include segmentation owing to negative pollution externalities or varying degrees of market failure. These three sets of factors indicate three effective avenues to promote domestic market unification. First, institutional market segmentation can be reduced by optimizing institutional design and eliminating local protectionism. Second, by increasing investment in transportation, information, and communication infrastructure and other public services, geographic divisions between regions can be bridged. Third, environmental regulations can be implemented to compensate for market failures, thereby eliminating spontaneous market segmentation through proactive governance.

While existing studies have often explained China's market fragmentation in terms of local protectionism and infrastructure issues (i.e., institutional and geographic factors), the impact of environmental regulations and market factors has been largely ignored, including in evaluations of market effectiveness. As an important component of social governance, environmental regulation promotes both environmental protection goals and technological progress. This is reflected in the “innovation compensation" effect (Ambec et al. 2013; Cai et al. 2020; Li et al. 2019; Peng 2020), wherein external spillover effects or positive externalities serve to reduce environmental pollution and promote technological progress (Fan et al. 2020; Li et al. 2021; Song et al. 2019; Zhang et al. 2020). Under China's "new normal" economic plan, environmental regulation has received 
significant attention, and green economic development has been promoted along with a focus on increasing labor productivity. $\mathrm{Li}$ and $\mathrm{Du}$ (2020) showed that environmental regulation has a significant spatial spillover effect on green innovation efficiency. Zhou et al. (2020) asserted that spatial spillover and industrial structure effects are the main pathways through which environmental regulations affect innovation, and $\mathrm{Hu}$ and Wang (2020) reported that environmental regulations have significant spillover effects on interprovincial carbon productivity in China. In these contexts, "spillover effects" represent the indirect effect of environmental regulations on reducing pollution and increasing productivity; therefore, they can compensate for certain environmental market failures, improve market efficiency, increase environmental welfare, and thus promote economic specialization (often referred to as "division of labor" by Chinese policymakers), thereby facilitating green economic development and technological progress by reducing domestic market segmentation.

Considering these benefits, local governments have emphasized environmental regulation after fiscal decentralization. However, when environmental regulations are extremely stringent, this can negatively impact market effectiveness and ultimately exacerbate market fragmentation. Therefore, research on the impact of environmental regulations on market segmentation, such as the present study, has clear theoretical and practical significance. This study aimed to demonstrate that fiscal decentralization leads to regional market segmentation by constructing an intertemporal decisionmaking model based on environmental welfare effects and to elucidate the theoretical mechanisms by which environmental regulations affect market segmentation. Based on spatial econometric methods, we also empirically analyzed the impact of environmental regulations on market segmentation and examined spatial spillover effects. Finally, we comprehensively discussed the role of fiscal decentralization in mediating the impact of environmental regulations on market segmentation, thereby further testing the reliability of the model.

\section{Intertemporal division of labor decision-making model based on environmental welfare effects}

Based on the approach of Lu et al. (2004) and Fan and Zhang (2010), we constructed an intertemporal division of labor decision-making model that considered the effects of environmental welfare. Here, we first considered the environmental welfare effect $\left(U_{1}\right)$, the microscopic effect on human welfare attributable to ecological improvements (Welsch 2007). The conditional valuation approach suggests that environmental welfare effect can be measured as the maximum cost that people are willing to pay for environmental improvements (Costanza et al. 1998). For example, the private costs of pollution are lower than the social costs, resulting in negative pollution externalities. This social cost can be considered as the cost that society is willing to pay to secure environmental improvements; therefore, the reduction in the environmental welfare effect caused by pollution is equivalent to its total social cost $\left(C_{s}\right)$. Studies have indicated that the higher a society's level of economic development $(y)$, the greater its preference for a good environment and therefore, greater 
the loss in social welfare owing to pollution (Givens and Jorgenson 2011; Stern 2004). Thus, the environmental welfare effect can be expressed as follows:

$$
U_{1}=C_{s}=M C_{s}(y) L
$$

where $M C_{s}(y)$ denotes the total marginal social cost of pollution, which increases with $y ; L$ represents the amount of pollution. We assume that the private marginal cost of pollution $\left(M C_{p}\right)$ and the total marginal social cost $\left(M C_{s}\right)$ do not vary with the amount of pollution. In a perfectly competitive market, the private marginal cost of pollution is the price of pollution $(P)$, i.e., the economic cost that the public is willing to pay for a unit of pollution (goods). Thus, we can obtain the socio-economic effect $\left(U_{2}\right)$ of pollution as follows:

$$
U_{2}=P * L=M C_{p} * L
$$

Since the social marginal cost of pollution is greater than the private marginal cost, the total social effect must decline when pollution occurs, as shown in Eq. (3).

$$
\Delta U=U_{2}-U_{1}=M C_{p} L-M C_{s}(y) L
$$

Negative externalities lead to an inconsistency between the private and social costs of pollution, contributing to price-signaling failures and a certain degree of environmental market inefficiency $(e)$, in which $e$ increases as the gap between the marginal social and private costs of pollution becomes larger. Therefore:

$$
e=K *\left[M C_{s}(y)-M C_{p}\right]
$$

where $K$ is a constant (for model simplicity $K=1$ ). From Eq. (1) and (4), we determine that as economic development levels increase, greater is the decrease in environmental welfare because of pollution and greater is the level of market inefficiency due to the negative externalities related to pollution. The adoption of environmental regulations (er) by a local government increases the private marginal cost of pollution; this new private marginal cost can be defined as follows:

$$
M C_{p(\text { new })}=M C_{p(\text { old })}+q(\text { er })
$$

where $q(e r)$ represents the increase in private marginal costs due to environmental regulations. Our simple inter-period division of labor decision-making model based on environmental welfare considers two regions (regions $A$ and $B$ ), two sectors (sectors $h$ and $l$ ), and two periods $\left(t_{1}\right.$ and $t_{2}$ ). Region $A$ has a higher degree of economic development; it has a comparative advantage in its $h$ sector, which has achieved a high level of technological development and is largely based on high-tech industries. Region $B$ has a comparative advantage in sector $l$, which has a low level of economic development and technology and is dominated by high-polluting and high-energyconsuming industries. Considering the objective existence of negative externalities due to environmental pollution, environmental markets usually suffer from severe market failures. Thus, we posit that such markets are characterized by severe inefficiency. In general, high-technology sectors, due to the nature of their products, have weaker connections with and are less affected by environmental markets, whereas low-technology sectors, which are often engaged in the production of highly polluting products, are typically more affected by environmental markets. Therefore, for 
model simplicity, we assumed that environmental market failures only exist in sector $l$ and region $B$.

The technological progress rate is faster in sector $h$ than in sector $l$; hence, we assumed a "learning by doing" effect in sector $h$ and no technological progress in sector $l$. To facilitate the model solution, we combined Eq. (3) and (4) based on the Cobb-Douglas effect function, an integrated effect function was constructed to account for environmental welfare effects:

$$
U=C^{h} * C^{l}-e * Y^{l}
$$

where $C^{h}$ and $C^{l}$ denote the consumption of products in sectors $h$ and $l$, respectively, and $Y^{l}$ denotes the production in sector $l$. We assumed that labor is the only input to the production process, and it was standardized as 1 . For model simplicity, we only considered the integration of product markets, while market factors were assumed to be completely segmented and labor was assumed to not be freely mobile across regions. Thus, the initial endowment of local labor is the labor input in production. The relative initial technology attainment and rate of technological advancement in sector $h$ in region $A$ are $g$ and $\phi$, respectively, while regions $A$ and $B$ have no technological advancement in sector $l$, and the initial technology is set as 1 .

\subsection{Intertemporal division of labor decision-making assuming no cross-zone commodity flow}

To consider the benefits of not dividing labor and assuming no time preference, regions $A$ and $B$ must maximize the sum of the effects of two periods:

$$
\max _{t_{1}, t_{2}} U=C_{1}^{h} * C_{1}^{l}+C_{2}^{h} * C_{2}^{l}-e\left(Y_{1}^{l}+Y_{2}^{l}\right)
$$

where $t_{1}$ and $t_{2}$ are the workforce assigned to sector $h$ in both periods; for region $A, e=0$. In this model, we could not accurately calculate the value of $e$ using Eq. (4). Therefore, we referred to the calculation results of Wang et al. (2010) and let $e=0.2$. We assumed that there is no return to scale in the production of $l$ sector, output is a linear function of time, and consumption is equal to output. To distinguish between regions $A$ and $B$, we used lowercase letters to indicate the effect and output of region $B$. Region $B$ has an initial technology and a rate of technological advancement of 1 regarding product $h$; its output in both phases is:

$$
\begin{gathered}
y^{l}=y_{1}^{l}+y_{2}^{l}=\left(1-t_{1}\right)+\left(1-t_{2}\right)=\left(2-t_{1}-t_{2}\right) \\
y^{h}=y_{1}^{h}+y_{2}^{h}=t_{1}+t_{1} * t_{2}
\end{gathered}
$$

Through simple linear projection, we determined that the resource allocation and effect in undeveloped region $B$ (without division of labor) are as follows:

$$
t_{1}=0.715 \quad t_{2}=0.640 \quad u=0.240
$$

Similarly, the output of developed region $A$ in the two sectors is:

$$
\begin{gathered}
Y^{l}=Y_{1}^{l}+Y_{2}^{l}=\left(1-t_{1}\right)+\left(1-t_{2}\right)=\left(2-t_{1}-t_{2}\right) \\
Y^{h}=Y_{1}^{h}+Y_{2}^{h}=g t_{1}+\phi Y_{1}^{h} t_{2}=g t_{1}+\phi g t_{1} t_{2}
\end{gathered}
$$

Therefore, the resource allocation and effects in the two periods are:

$$
T_{1}=\frac{1}{2}+\frac{1}{8} \phi \quad T_{2}=\frac{1}{2} \quad U=g *\left(\frac{1}{2}+\frac{1}{8} \phi\right)^{2}
$$


Here, we used the condition of undivided labor (no economic specialization) to represent extreme market segmentation, where production equals consumption in both regions and the commodity market is completely separate. If this model represents the rational choice for lagging region $B$, then the implementation of environmental regulation would improve market efficiency and allow the region to participate in the division of labor, it implies that the effect is larger than the above-mentioned part of the effect (without division of labor).

\subsection{Intertemporal division of labor decision-making model assuming inter-regional commodity flow}

We assumed that market integration entails a perfect division of labor (complete economic specialization), wherein the lagging region $B$ allocates all its resources to the production of product $l$, with an output of 1 in each period. The developed region $A$ is responsible for the production of product $h$; the output in the first phase is $g$, and that in the second phase is $\phi g$. Complete market integration indicates that products $l$ and $h$ can be freely exchanged; it is assumed that the price of product $l$ is 1 , and the price of product $h$ is $p(p>1)$. The transportation cost between regions is represented as an "iceberg" cost. Assuming 1 unit of product is transported from one region to another, only $1 / D$ units $(D>1)$ of products can reach the destination ( $D$ represents the transportation conditions between the two regions). Thus, the maximum two-period sum of effects in region $B$ is:

$$
\begin{gathered}
\max _{c_{1}^{h}, c_{2}^{h}} u=c_{1}^{h} * c_{1}^{l}+c_{2}^{h} * c_{2}^{l}-e\left(y_{1}^{l}+y_{2}^{l}\right) \\
\text { s.t. }\left\{\begin{array}{c}
c_{1}^{l}+D p c_{1}^{h}=1 \\
c_{2}^{l}+D p c_{2}^{h}=1 \\
y_{1}^{l}+y_{2}^{l}=2
\end{array}\right.
\end{gathered}
$$

Solving the linear programming problem yields:

$$
u=c_{1}^{h}-0.4=c_{2}^{h}-0.4=\frac{1}{2 D p}-0.4
$$

Similarly, the effect in developed region $A$ is:

$$
C_{1}^{h}=\frac{g}{2} \quad C_{2}^{h}=\frac{\phi g}{2} \quad U=\frac{g^{2} p}{4}\left(1+\phi^{2}\right)
$$

Under static division of labor conditions, the effect in lagging region $B$ is impaired, and the following condition must be met:

$$
\frac{1}{2 D p}-0.4 \leq 0.240
$$

Because $D>1$ and $P>1$, Eq. (17) will be satisfied under normal conditions. At this time, if region $B$ implements environmental regulations, it can be concluded from Eqs. (3) and (5) that the overall environmental welfare effect will increase (we also address special circumstances when environmental regulations can cause the overall welfare effect to decline).

When environmental regulation is implemented in region $B$, through Eqs. (4), (5), and (7), we obtain: 


$$
U^{*}=\frac{1}{2 D p}-0.4+2 q(e r)
$$

where $U^{*}$ represents the effect of implementing environmental regulations in region $B$, and $q(\mathrm{er})$ represents the improvement in market efficiency due to environmental regulations. When $q(e r)=$ 0.2 , environmental regulations completely compensate for environmental market failures.

By contrasting Eqs. (10) and (13) with Eqs. (15) and (16), we can determine that the environmental welfare effect actually decreases in region $B$ under divided labor and completely free trade. This suggests that under both decentralization and a free market, the lagging region would rationally choose not to divide labor and to adopt the strategy of market segmentation to achieve greater economic gains. However, developed region $A$ would receive the entire benefit of the "learning by doing" effect of the division of labor, and higher the relative price of product $h$, the higher the initial skill level, and faster the technological progress, more the benefit to region $A$ stands; thus, the division of labor is more beneficial to region $A$. For environmental regulations to ensure that both regions are willing to integrate into a specialized economic system, the benefits of the specialization must exceed the associated threats, thus satisfying the following formula:

$$
0.640-\frac{1}{2 D p} \leq 2 q(e r)
$$

Since $p>1$, Eq. (19) also indicates that the greater the technological gap between regions, the greater the transportation costs and the greater the intensity of environmental regulations needed to make region $B$ willing to integrate into the division of labor system.

To simplify the model, we assumed that production factors cannot flow freely. If we relax this assumption, then under the conditions of division of labor, when environmental regulations are implemented in region $B$, according to the "pollution haven" theory (Candau and Dienesch 2017; Shao et al. 2019a), the production factors of sector $l$ will be transferred to region $A$, thus increase pollution in region $A$ and reduce the environmental welfare effect. In this scenario, region $A$ will often adopt a non-division of labor strategy; therefore, the implementation of local environmental regulations may lead to aggravated market segmentation in neighboring regions.

\section{Evolution of environmental regulation and market segmentation}

We used the "relative price method" to measure the degree of market segmentation in China, For specific calculation methods, please refer to Lu and Chen (2009). The "price method" measures the degree of market integration using data on the differences in the relative price of various commodities between regions. Then, trends in these relative prices are considered over time. If the price trends converge, it indicates that the transaction costs between regions have decreased, a sign of market integration. Fig. 1 presents trends in the degree of market segmentation in China from 2004-2018. 


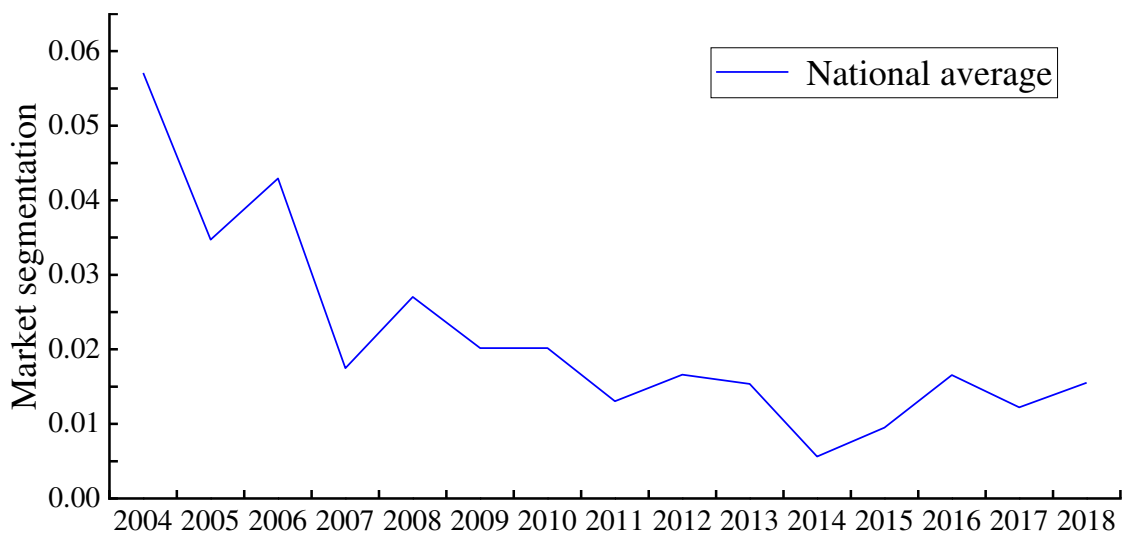

Fig. 1 Market segmentation trends in China

Fig. 1 demonstrates that since 2004, market segmentation in China has declined overall, which is consistent with the findings of existing research (Gui et al. 2006; Shao et al. 2019b; Wu et al. 2020). In 2014, market segmentation fell to its lowest level ever, but in 2015, the index increased significantly as compared to the previous year, which may have been related to the implementation of new environmental protection laws in China. The market segmentation index declined from 0.057 in 2004 to 0.016 in 2018 with an average annual decline of $8.88 \%$, suggesting that many local governments increasingly abandoned their compartmentalized incentives and integrated better into global and domestic markets.

Regions with different economic development levels typically have different degrees of market segmentation, and those with different resource endowments and geographic conditions may adopt different market segmentation strategies to gain greater economic benefits. Therefore, in Fig. 2, we present market segmentation trends within trend broad regions of China: east, central, and west. At the regional level, the overall national trend largely prevailed, with a downward trend followed by a slight increase around 2015. The level of market segmentation was generally the highest in the western region before 2014 and in the eastern region after 2014. The average annual rate of decline in the eastern, central, and western regions over 2004-2018 was 7.46, 9.45, and 9.92\%, respectively. We note that the western region's market segmentation index declined the fastest and to a greater extent than the national average, whereas that in the east declined the slowest.

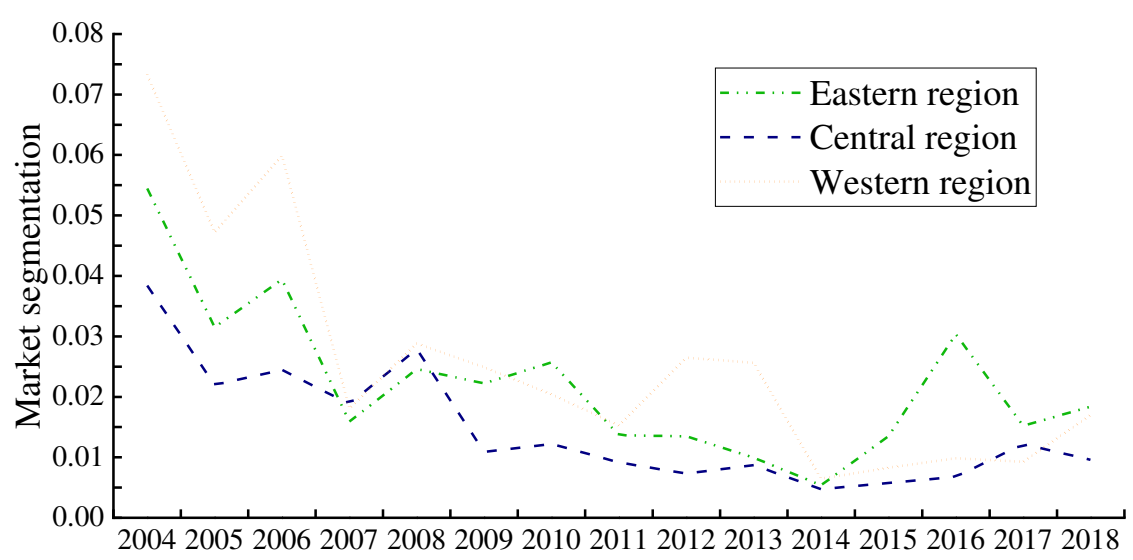


We used the ratio of investment in industrial pollution control to the main cost $(E R 1)$ and value added of industrial enterprises above a designated size (ER2) to measure the intensity of environmental regulation (Berman and Bui 2001; Zhang et al. 2011). ER1 was used as a measure of environmental regulatory intensity and $E R 2$ as a stability test. Fig. 3 and 4 present temporal trends in the intensity of environmental regulations in China and its three major regions, and IPC represents the total investment in industrial pollution control. Fig. 3 indicates that the intensity of environmental regulations in China generally presented a marked decrease until 2012, after which widespread academic consensus maintained that rapid economic development in China would be dependent on large investments in resources and the environment. In 2013, after the introduction of the "new [economic] normal," the intensity of environmental regulations increased to a local maximum in 2014 and then declined again. This is mainly because of the continuous transformation and upgrading of China's industries since the "new normal" and the continuous advancement of green technology, which has made it possible to achieve environmental protection goals with a relatively low intensity of environmental regulations. However, Fig. 4 demonstrates clear geographical variations in environmental regulation intensity. Specifically, the average environmental regulatory intensities during 2004-2017 were $0.107,0.160$, and 0.265 in the eastern, central, and western regions, respectively.

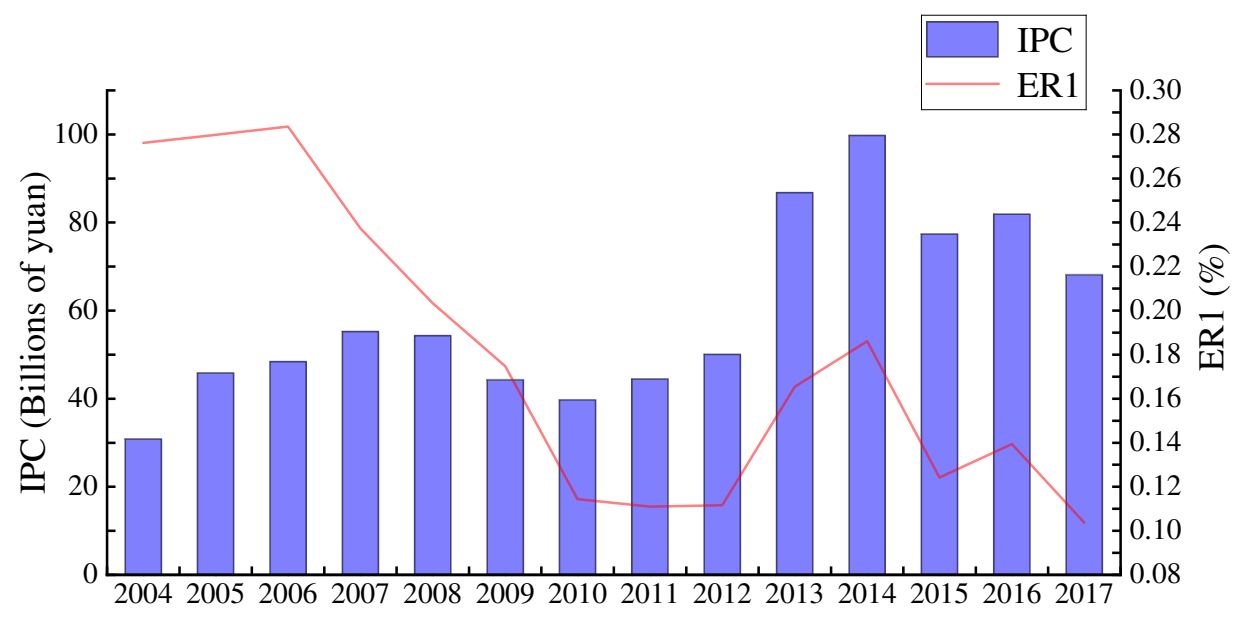

Fig. 3 Trend of environmental regulatory intensity in China. IPC: investment in industrial 


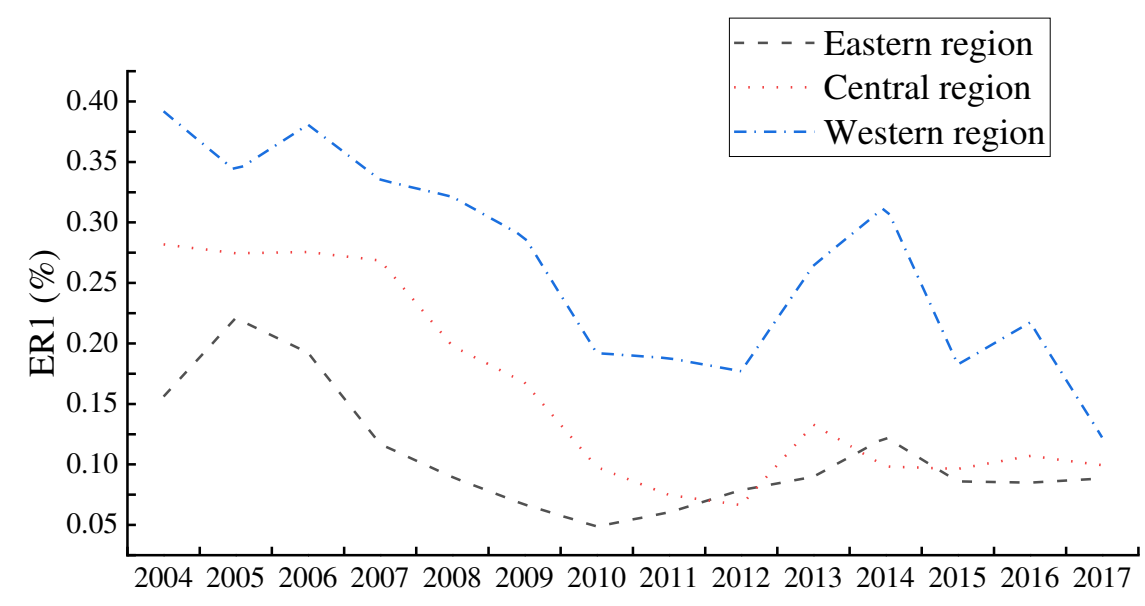

Fig. 4 Changes in environmental regulatory intensity by region

The implementation of environmental regulations directly compensates for some environmental market failures, resulting in increased inter-regional market efficiency and changes in regional economic strategies. To accelerate the process of market integration between different regions, the establishment of different environmental regulatory policies could be a primary strategy adopted by local governments. When we compare temporal trends in market segmentation and environmental regulation, we see that market segmentation reached a local minimum in 2014 and environmental regulation reached a local maximum in 2014, the first official year of the "new normal" economic plan. This shows that macroeconomic policies have a great impact on national market integration and environmental protection. We also note that market fragmentation declines more rapidly in the West when a higher intensity of environmental regulations is adopted in this region. This is because the implementation of environmental regulatory policies in the West makes the region more willing to cooperate with the East in the division of labor and promotes market integration. Although in the second part of this study, the specific impact mechanism of environmental regulation on market segmentation is modeled and analyzed, there is no empirical evidence that environmental regulations break down domestic market segmentation; hence, the effect of environmental regulations on market segmentation needs to be further verified through empirical analysis. In the empirical analysis described in Section 4, to avoid underestimating the regression coefficients, we multiplied the environmental regulation coefficient by 1000 .

\section{Empirical Analysis}

\subsection{Spatial correlation analysis}

We determined whether China's market segmentation was spatially autocorrelated using Moran's $I$ test, which identifies the correlation between an observed value and its spatial lag with values ranging from -1 to 1 . Before calculating Moran's $I$ index, we first constructed the spatial weight matrix $W_{i j}$ for each province as follows: 
Table 1 shows that Moran's $I$ index of China's market segmentation supports our hypothesis at either the $1 \%$ or $5 \%$ significance level, except for 2007. Thus, market segmentation in China's 30 provinces has a significantly positive correlation with spatial distribution (i.e., spatial dependence) and therefore, is not random.

Table 1 Moran's $I$ index values

\begin{tabular}{lllllllll}
\hline Year & 2004 & 2005 & 2006 & 2007 & 2008 & 2009 & 2010 & 2011 \\
\hline Moran's $I$ & $0.400^{* * *}$ & $0.409^{* * *}$ & $0.295^{* * *}$ & 0.149 & $0.433^{* * *}$ & $0.533^{* * *}$ & $0.321^{* * *}$ & $0.235^{* * *}$ \\
\hline Year & 2012 & 2013 & 2014 & 2015 & 2016 & 2017 & 2018 & \\
\hline Moran's $I$ & $0.358^{* * *}$ & $0.392^{* * *}$ & $0.181^{* *}$ & $0.416^{* * *}$ & $0.476^{* * *}$ & $0.596^{* * *}$ & $0.246^{* *}$ &
\end{tabular}

Note: ***, **, and * indicate significance at the $1 \%, 5 \%$, and $10 \%$ significance levels, respectively.

Exponential scatterplots of Moran's I values can divide provincial market segmentation clusters into four quadrants indicating different spatial correlation patterns: quadrant one $(\mathrm{HH})$ indicates areas with high market segmentation surrounded by other areas with high market segmentation; quadrant 2 (LH) indicates areas with a low degree of market segmentation surrounded by areas with high market segmentation; quadrant 3 (LL) indicates areas with low market segmentation surrounded by areas with low market segmentation; and quadrant 4 (HL) indicates areas with high market segmentation surrounded by areas with low market segmentation. The first and third quadrants reflect positive spatial autocorrelation, while the second and fourth quadrants reflect negative spatial correlation. We created a scatterplot of Moran's $I$ index values for market segmentation in 2004 and 2018, as shown in Fig. 5.
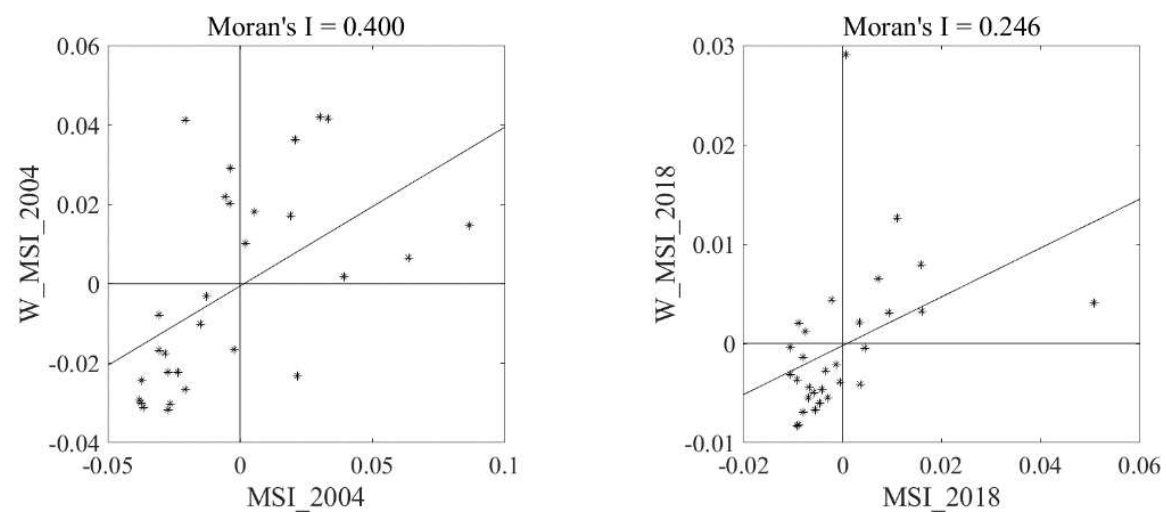

Fig. 5 Scatterplot of Moran's $I$ index (MSI) for provincial market segmentation in China in 
Fig. 5 shows that most of Chinese provinces are located in quadrant 1 (HH) or quadrant 3 (LL).

380 Eight provinces were in quadrant 1 in 2018, the same as in 2004, and 16 provinces were in quadrant 3813 in 2018, two more than in 2004. Overall, $80.00 \%$ (2004) and $73.33 \%$ (2018) of the total sample fell into quadrants 1 and 3 . These results further confirm the significant spatial dependence of

383 China's provincial market segmentation, with most provinces exhibiting cluster characteristics similar to those of their neighbors.

\subsection{Model construction and data sources}

From Section 2.3, we can see that Chinese provincial market segmentation has significant spatial autocorrelation, and the impact of environmental regulations on market segmentation may also have spatial spillover effects, that is, foreign environmental regulations may affect local market segmentation. Therefore, we adopted a specific-to-general approach and selected a spatial Durbin model (SDM) to analyze the phenomenon of provincial market segmentation in China.

$$
M S I_{i, t}=\rho W_{i, j} M S I_{i, t}+X_{i, t-1} \beta+W_{i, j} X_{i, t-1} \theta+\varepsilon_{i, t}
$$

In Eq. (21), $X_{i, t-1}$ denotes the explanatory variable, $\rho$ is the spatial autoregressive coefficient of market segmentation, $\beta$ denotes the coefficient of the explanatory variable, $\theta$ denotes the coefficient of the spatially lagged term of the explanatory variable, and $\varepsilon_{i, t}$ is the error term. To mitigate the endogeneity problem, we lagged all explanatory variables by one period. Since a nonlinear relationship may exist between environmental regulation and market segmentation, we introduced the squared term of environmental regulation, $E R^{2}$, into the equation. Regarding the explanatory variables, we first focused on their coefficients and significance of the environmental regulation $E R 1$ and its squared term $E R 1^{2}$. For the control variables, we used the ratio of the main business income of state-controlled industrial enterprises to the main business income of industrial enterprises above a designated size to depict the degree of enterprise ownership (SOE). The degree of regional economic development ( $P G D P$ ) is expressed in terms of GDP per capita (million yuan); the degree of fiscal decentralization $(F D)$ is expressed in terms of the ratio of the regional budget per capita to the national budget per capita, and the level of regional logistics $(L L)$ is measured in terms of freight turnover (trillion tonne-kilometers).

All data were obtained from the China Statistical Yearbook (2005-2018b) and the China Statistical Yearbook on Environment (2005-2018a). We excluded Hong Kong, Macau, Taiwan, and Tibet due to differences in economic systems and data availability. The study's sample set consisted

412 of 420 sample observations in 30 cross-sections for the 2004-2018 period. Descriptive statistics of the variables are shown in Table 2. 


\begin{tabular}{lllllll}
\hline Abbreviation & Index & Mean & $\begin{array}{l}\text { Standard } \\
\text { deviation }\end{array}$ & $\begin{array}{l}\text { Min } \\
\text { value }\end{array}$ & $\begin{array}{l}\text { Max } \\
\text { value }\end{array}$ & Observations \\
\hline$M S I$ & Market segmentation index & 0.022 & 0.023 & 0.002 & 0.182 & 450 \\
ER1 & $\begin{array}{l}\text { Environmental regulatory } \\
\text { intensity }\end{array}$ & 0.180 & 0.161 & 0.008 & 1.194 & 420 \\
$S O E$ & Enterprise ownership & 0.405 & 0.193 & 0.096 & 0.837 & 420 \\
$P G D P$ & Level of economic development & 3.697 & 2.420 & 0.432 & 12.899 & 420 \\
$F D$ & Degree of fiscal decentralization & 0.972 & 0.483 & 0.413 & 3.438 & 420 \\
$L L$ & Logistics level & 0.423 & 0.442 & 0.014 & 2.792 & 420 \\
\hline
\end{tabular}

\subsection{Empirical results}

As shown in Table 3, both the likelihood ratio (LR) and Wald test results indicated that the SDM did not degenerate into spatial error (SEM) or spatial lag (SAR) models and was thus appropriate for use in the context of this study. We conducted an LR test on the spatial fixed-effects model, and the results (estimated value of $57.5339, p<0.01$ ) indicated that we could reject the original hypothesis that the model was jointly independent of spatial fixed-effects. We also performed an LR test on the fixed temporal effects model and again obtained results that failed to support the original hypothesis (estimated value of 82.3028, $p<0.01$ ). The LR test confirmed that the model could be extended to a spatial Durbin model with fixed spatiotemporal effects (SDM (FE)). Therefore, the SDM (FE) was used as a reference, and we also estimated the results of the SDM with random effects.

Table 3 Effects of environmental regulation (ER1) on market segmentation

\begin{tabular}{lllll}
\hline Variables & $(1)$ & $(2)$ & $(3)$ & $(4)$ \\
\cline { 2 - 5 } & SDM (FE) & SDM $(\mathrm{RE})$ & $\mathrm{SDM}(\mathrm{FE})$ & $\mathrm{SDM}(\mathrm{RE})$ \\
\hline$E R 1$ & $-0.054^{* * *}(-4.005)$ & $-0.035^{* * *}(-3.096)$ & $-0.052^{* * *}(-3.788)$ & $-0.036^{* * *}(-3.096)$ \\
$E R 1^{2}$ & $0.004^{* * *}(2.970)$ & $0.003^{* *}(2.025)$ & $0.004^{* * *}(2.845)$ & $0.003^{* *}(2.098)$ \\
$F D$ & $0.173^{* *}(3.239)$ & $0.108^{* * *}(5.240)$ & $0.100^{* *}(2.429)$ & $0.093^{* * *}(3.954)$ \\
$E R^{*} F D$ & & & $0.060^{* * *}(2.825)$ & $0.034^{* *}(1.979)$ \\
$S O E$ & $0.187^{* *}(2.316)$ & $0.009^{* *}(2.173)$ & $0.133^{* * *}(2.863)$ & $0.022^{* *}(1.983)$ \\
$P G D P$ & $-0.021^{* *}(-1.973)$ & $-0.009^{*}(-1.686)$ & $-0.016^{*}(-1.701)$ & $-0.010^{* *}(-2.320)$ \\
$L L$ & $-0.012(-0.391)$ & $-0.007(-0.370)$ & $-0.018(-0.569)$ & $-0.013(-0.615)$ \\
$W^{*} E R 1$ & $0.062^{* *}(1.963)$ & $0.053^{* *}(2.126)$ & $0.045^{* *}(1.979)$ & $0.045^{*}(1.770)$ \\
$W^{*} E R 1^{2}$ & $-0.009^{* *}(-1.971)$ & $-0.006^{*}(-1.643)$ & $-0.007^{* *}(-2.260)$ & $-0.006(-1.526)$ \\
$W^{*} F D$ & $-0.318^{* * *}(-3.092)$ & $-0.100^{* *}(-2.349)$ & $-0.227^{* *}(-1.961)$ & $-0.120^{* * *}(-2.666)$ \\
$W^{*} E R I^{*} F D$ & & & $0.031(0.472)$ & $0.040(1.230)$ \\
$W^{*} S O E$ & $-0.095(-0.335)$ & $0.084(0.930)$ & $0.219(0.661)$ & $0.194^{*}(1.873)$ \\
$W^{*} P G D P$ & $0.064^{* * *}(2.613)$ & $0.005^{* *}(2.539)$ & $0.067^{* * *}(2.707)$ & $0.015^{*}(1.770)$ \\
$W^{*} L L$ & $-0.031(-0.681)$ & $0.009(0.256)$ & $-0.043(-0.944)$ & $-0.003(-0.080)$ \\
$W^{*}$ dep.var & $0.684^{* * *}(18.686)$ & $0.735^{* * *}(21.700)$ & $0.684^{* * *}(18.692)$ & $0.729^{* * *}(21.554)$ \\
intercept & & $0.011(0.268)$ & & $-0.031(-0.577)$ \\
\hline & & & \\
\hline
\end{tabular}




\begin{tabular}{|c|c|c|c|c|}
\hline$\overline{\text { teta }}$ & & $0.853^{* * *}(6.973)$ & & $0.776^{* * *}(6.728)$ \\
\hline$\sigma^{2}$ & 0.0148 & 0.0150 & 0.0146 & 0.0147 \\
\hline$R^{2}$ & 0.6273 & 0.5783 & 0.6309 & 0.5873 \\
\hline $\log -L$ & 281.342 & 244.086 & 283.403 & 246.613 \\
\hline$W-L$ & $22.1027^{* * *}$ & & $19.8483^{* * *}$ & \\
\hline$W-E$ & $17.2316^{* * *}$ & & $16.7705^{* * *}$ & \\
\hline$L-L$ & $23.4316^{* * *}$ & & $21.7501^{* * *}$ & \\
\hline$L-E$ & $14.7562^{* *}$ & & $20.0238^{* * *}$ & \\
\hline
\end{tabular}

Note: t-test values are shown in parentheses; ${ }^{* * *},{ }^{* *}$, and $*$ indicate significance at the $1 \%, 5 \%$, and $10 \%$ levels, respectively; SDM: spatial Durbin model; FE: fixed spatiotemporal effects; RE: random effect.

From column (1) of Table 3, we note that the coefficient of environmental regulation is positive, and the coefficient of its squared term is negative. Both coefficients are significant at the $1 \%$ level. Therefore, environmental regulation contributes to market integration when the intensity of environmental regulation is low, while it exacerbates market fragmentation when the intensity of environmental regulation exceeds a certain threshold value (an environmental regulation coefficient of 6.079$)$. More than $97.86 \%$ of the 450 observations had environmental regulation intensities below this value, indicating that under current conditions, an appropriate increase in the level of environmental regulation would promote market integration. The coefficient of fiscal decentralization was significantly positive, suggesting that fiscal decentralization exacerbates market segmentation, which is consistent with the results of Li et al. (2003). The coefficient of enterprise ownership was significantly positive, indicating that the larger the share of state-owned enterprises (SOEs), the more likely that local governments will adopt local protection strategies to protect the interests of SOEs and thereby exacerbate market fragmentation. The coefficient of GDP per capita was negative at the 5\% significance level, suggesting that increased economic development can promote market integration. The level of economic development often reflects the technological advancement in a region, as in our model - the higher the level of local technology, the greater the local incentive to adopt division of labor. The coefficient of the level of logistics was not significant (likely because this variable does not fully reflect transportation costs); however, in our model, reducing transportation costs between two locations can mitigate market segmentation.

In terms of spatial effects, Table 3 shows that environmental regulations have a significant spatial spillover effect on market segmentation, and environmental regulations in neighboring regions have a significant nonlinear effect on the level of market segmentation in a region. Specifically, when the intensity of environmental regulations in surrounding areas is less than 3.431, environmental regulations in these neighboring areas can significantly increase market segmentation in the region; more than $86.43 \%$ of the 450 observations presented environmental regulatory intensity less than this threshold. Therefore, under the scenario, market segmentation can be exacerbated by environmental regulations in neighboring regions. When a neighboring region implements environmental regulations, on the one hand, the neighboring region increases its market 
efficiency, relatively lowering the local market efficiency. Local production factors will be attracted to the neighboring region; thus, to retain production factors locally, the rational strategy is to pursue market segmentation. On the other hand, according to the "polluting paradise" theory, when polluting firms from neighboring areas move to a local area, the local area may adopt a market segmentation strategy to avoid a decrease in the overall environmental welfare effect.

Regarding the other control variables, greater fiscal decentralization in neighboring regions reduced the degree of market segmentation locally, mainly because when neighboring regions intervened more heavily in the market, it resulted in a decrease in the efficiency of resource allocation to the market; the losses from such decreases in market efficiency far outweigh the gains. Therefore, a local region can benefit more from economic specialization and thus will be more inclined to pursue this strategy. An increased GDP per capita in a neighboring region significantly increased the degree of local market segmentation because as the neighboring region's level of economic development rose, its technological advancement increased as well; therefore, the local region was more disadvantaged by specialization and would rationally choose to pursue segmentation instead. The spatial effects of the other control variables were not significant. Notably, the coefficient of $W^{*}$ dep.var was significantly positive, confirming the strong spatial autocorrelation of market segmentation.

Having demonstrated the U-shaped effect of environmental regulations on market segmentation, we explored whether this effect changed in regions with different degrees of fiscal decentralization. To do so, we introduced an interaction term between environmental regulation and fiscal decentralization into the model. To eliminate the effects of multicollinearity, we deaveraged the interaction terms, and as shown in column (3) of Table 3, we found that the interaction term was positive at the $1 \%$ significance level. This suggests that when the intensity of environmental regulation is low, increasing the intensity of environmental regulation can significantly promote domestic market integration and that increasing the degree of fiscal decentralization enhances this effect. When the degree of environmental regulation is high, increasing the intensity of environmental regulation can significantly dampen domestic market consolidation, while fiscal decentralization can mitigate this negative effect.

Table 4 Effects of environmental regulation (ER2) on market segmentation

\begin{tabular}{lllll}
\hline \multirow{2}{*}{ Variables } & $(1)$ & $(2)$ & $(3)$ & $(4)$ \\
\cline { 2 - 5 } & SDM (FE) & SDM (RE) & SDM (FE) & SDM (RE) \\
\hline$E R 2$ & $-0.217^{* * *}(-3.961)$ & $-0.138^{* * *}(-3.104)$ & $-0.206^{* * *}(-3.756)$ & $-0.145^{* * *}(-3.188)$ \\
$E R 2^{2}$ & $0.071^{* * *}(3.006)$ & $0.041^{* *}(1.961)$ & $0.068^{* * *}(2.889)$ & $0.045^{* *}(2.117)$ \\
$F D$ & $0.176^{* * *}(3.356)$ & $0.109^{* * *}(5.353)$ & $0.101^{*}(1.662)$ & $0.094^{* * *}(4.037)$ \\
$E R 2^{*} F D$ & & & $0.060^{* *}(1.847)$ & $0.036^{* *}(2.068)$ \\
$S O E$ & $0.157^{* * *}(3.134)$ & $0.007^{*}(1.730)$ & $0.100^{* *}(2.167)$ & $0.018^{*}(1.818)$ \\
$P G D P$ & $-0.025^{* *}(1.970)$ & $-0.010^{*}(-1.720)$ & $-0.019^{* * *}(-2.669)$ & $-0.010^{* *}(-2.411)$ \\
$L L$ & $-0.012(-0.378)$ & $-0.005(-0.258)$ & $-0.017(-0.543)$ & $-0.011(-0.522)$ \\
\hline
\end{tabular}




\begin{tabular}{lllll}
\hline$W^{*} E R 2$ & $0.257^{* *}(2.012)$ & $0.222^{* *}(2.294)$ & $0.195(1.484)$ & $0.188^{*}(1.878)$ \\
$W^{*} E R 2^{2}$ & $-0.153^{* *}(-2.058)$ & $-0.134^{* *}(-2.174)$ & $-0.129^{*}(-1.722)$ & $-0.119^{*}(-1.885)$ \\
$W^{*} F D$ & $-0.303^{* * *}(-3.043)$ & $-0.090^{* *}(-2.223)$ & $-0.214^{* *}(-1.906)$ & $-0.110^{* *}(-2.521)$ \\
$W^{*} E R 2^{*} F D$ & & & $0.031(0.462)$ & $0.040(1.213)$ \\
$W^{*} S O E$ & $-0.085(-0.306)$ & $0.105(1.221)$ & $0.212(0.666)$ & $0.210^{* *}(2.150)$ \\
$W^{*} P G D P$ & $0.065^{* * *}(2.655)$ & $0.005(0.564)$ & $0.066^{* * *}(2.717)$ & $0.014(1.360)$ \\
$W^{*} L L$ & $-0.030(-0.674)$ & $0.011(0.335)$ & $-0.042(-0.932)$ & $0.000(0.014)$ \\
$W^{*}$ dep.var & $0.674^{* *}(18.059)$ & $0.738^{* * *}(22.790)$ & $0.682^{* * *}(18.555)$ & $0.713^{* * *}(20.800)$ \\
intercept & & $-0.002(-0.039)$ & & $-0.041(-0.768)$ \\
teta & & $0.874^{* * *}(7.039)$ & & $0.785^{* * *}(6.767)$ \\
$\sigma^{2}$ & 0.0149 & 0.0151 & 0.0147 & 0.0148 \\
$R^{2}$ & 0.6254 & 0.5778 & 0.6303 & 0.5842 \\
Log-L & 281.106 & 244.771 & 283.205 & 247.461 \\
$W-L$ & $22.0602^{* * *}$ & & $19.5559^{* * *}$ & \\
$W-E$ & $14.5086^{* *}$ & & $16.2417^{* *}$ & \\
$L-L$ & $23.4921^{* * *}$ & & $21.4656^{* * *}$ & \\
$L-E$ & $16.8070^{* * *}$ & & $19.4725^{* * *}$ & \\
\hline Note: & & & &
\end{tabular}

Note: t-test values are shown in parentheses; ***,**, and * indicate significance at the $1 \%, 5 \%$, and $10 \%$ levels, respectively; SDM: spatial Durbin model; FE: fixed spatiotemporal effects; RE: random effect.

To verify the stability of the empirical results, we selected $E R 2$ as a proxy for environmental regulatory intensity while continuing to use the fixed-effects SDM for a regression analysis; the empirical results are shown in Table 4. We found that environmental regulations still had a U-shaped effect on market segmentation, and the interaction term between environmental regulations and fiscal decentralization remained significantly positive. The estimated coefficients of the control variables were similar to the results shown in Table 3 , indicating that the estimates of ER1 and ER2 were generally consistent. Therefore, the regression results obtained in this study are robust.

\section{Discussion}

Recent research indicates that environmental regulations reduce environmental pollution while partially compensating for market failures (Chang et al. 2018; Lee 2006; Testa et al. 2011; Zhang et al. 2018). The negative pollution externalities caused by lack of clearly defined property rights lead to a certain degree of market failure in environmental markets, where the private costs of discharging pollution are smaller than the social costs; thus, the pollution emissions of enterprises tend to be much larger than the optimal social carrying capacity (Reinhardt 1999), thereby decreasing the total social environmental welfare effect. Environmental regulation directly affects polluting firms, increasing their private emissions costs, internalizing external costs, reducing pollution emissions, increasing the overall environmental welfare effect, and partially compensating for environmental market failures. However, pollution tends to be upstream in the supply chain, and environmental market failures can result in pollution being sold to downstream firms at lower prices; therefore, the prices of goods produced via pollution are necessarily lower than is optimal for downstream firms, 
causing price failures and triggering more significant failures in the commodity market. Thus, environmental regulation can also compensate for broader commodity market failures.

Market failures inevitably lead to decreased market efficiency, such as resource mismatches; better resource allocation could increase the overall social environmental welfare effect (Clinch and Healy 2000; Izquierdo and Izquierdo 2007). Thus, as the degree of market failure decreases, the total social effect must increase (Bator 1958). In this context, more developed regions experience more significant benefits from labor division, as they usually have relatively efficient markets and comparative advantages in technologically advanced sectors. In lagging regions, industries with comparative advantages are usually high-polluting, high-energy-consuming industries with greater links to environmental markets; increased division of labor would indicate that lagging regions would have to increase commodity production in these industries. Owing to the objective existence of environmental market failures, lagging regions must produce more at prices lower than the social environmental welfare cost. Therefore, the rational choice for these regions is to pursue market segmentation. However, when a certain degree of environmental regulation is implemented, the economic effect decreases to some extent, but the environmental welfare effect increases; if the latter is greater than the former, it can indirectly cause lagging regions to abandon the segmented market strategy, and economic specialization can be promoted at the national level, thereby improving overall market efficiency.

Fiscal decentralization allows for increased individual rights and a more rational distribution of authority between the central and local governments, without forcing each region to wholly fend for itself. Decentralization also indicates that local governments can implement more appropriate regulatory policies based on their own levels of development (Chen and Chang 2020; Mao 2018; Treisman 2006). Our results suggest that local governments could better use environmental regulations to promote market integration in more decentralized areas. On the one hand, local governments better understand market failures in their regions than the central government. Thus, with the same intensity of environmental regulation, local governments with a higher degree of decentralization can develop environmental regulatory policies that are well-suited to their market conditions. Further, under increased environmental regulation, the overall effect of labor division in lagging regions becomes greater, making market integration a more rational choice for such regions. Thus, the role of environmental regulation in promoting market integration is more pronounced in regions with greater decentralization.

Environmental regulation can improve market efficiency and increase the overall environmental welfare effect, which typically leads local governments to move away from local protectionism and toward market integration. However, some countries and regions continue to voluntarily reduce the intensity of environmental regulations for three main reasons. First, local governments usually consider the overall environmental welfare effect and formulate appropriate environmental regulatory policies. For example, under China's "new normal" economy, its people, in addition to their growing material and cultural needs, have become increasingly interested in 
maintaining a good ecological environment. Therefore, the Chinese government, while actively pursuing economic development, is also paying more attention to environmental protection. However, "rent-seeking" on the part of local governments can cause them to discount overall environmental welfare effects and lead to governmental regulatory failures. Second, in extremely poor countries or regions, the fulfillment of basic needs supersedes environmental welfare. The effects of basic necessities tend toward the infinite, leading to a decrease in the overall effects of environmental regulations, which we do not discuss in detail here. Finally, when the present value of expected returns on invested capital in year $t$ is greater than the current environmental welfare effect, that is:

$$
M C_{p} L\left[1+e^{(\varphi-r) t}\right]>M C_{s}(y) L
$$

where $r$ is the discount rate, and $\varphi$ is the expected return on capital investment. In an environmental welfare effect-based intertemporal decision-making model, the right side of the equation represents the total social cost (i.e., the environmental welfare effect), and the left side of the equation represents the present value of the expected return on capital investment. When the above equation holds, the implementation of environmental regulations leads to a decrease in the overall regional effect, and the rational choice of local governments is to sacrifice the environment for economic gains. It is worth noting that the above equation is valid when $\varphi>r$ and $t \rightarrow+\infty$. In this case, local governments usually make comprehensive decisions that account for temporal costs. Therefore, countries with higher rates of return on investment (i.e., developing countries) may pursue the strategy of relaxing environmental regulations. As economically developed countries are likely to have diminished marginal returns on capital investment, the above conditions are less likely to occur; thus, these countries tend to have a greater preference for environmental welfare (which implies a higher social cost related to pollution).

\section{Conclusions}

In the context of fiscal decentralization in China, the mitigation of market segmentation and the development of an efficient free-market mechanism while protecting the environment is an important goal. Therefore, based on spatial econometric theory, we employed an SDM to empirically study the relationship between the intensity of environmental regulations and market segmentation in China using interprovincial panel data from 2004-2018. Based on the empirical findings and the above discussion, we present the following conclusions and recommendations.

First, the spatial agglomeration effect of market segmentation is evident, and the "beggar-thyneighbor" phenomenon persists in China. The main reason for the increased market fragmentation between regions is the pursuit of greater local economic benefits (partial for the personal gain of local officials). However, current research suggests that way local protectionism may be the dominant approach, it is always not the best strategy (Ke 2015; Lu and Chen 2009). Therefore, accounting for the economic development of each region, the central government should guide local governments at the policy level, actively promote regional integration strategies and strengthen 
cross-provincial cooperation to realize complementary advantages. Local governments should work to accurately assess their own positions, accept the guidance of the central government, and avoid excessive artificial intervention in the market, allowing market forces to play a decisive role in the allocation of resources.

Second, environmental regulations have a U-shaped effect on market segmentation. When the intensity of environmental regulations is not too high, increasing their intensity promotes market integration. However, if the intensity of environmental regulations exceeds a certain threshold, increasing them discourages market integration. Our results suggest, however, that in the vast majority of cases in China (specifically, more than $97.86 \%$ of the observation points), environmental regulation would facilitate market consolidation while reducing environmental pollution and promoting increased productivity through "innovation compensation" mechanisms. This is because environmental regulations reduce the negative externalities of pollution, partially compensate for market failures, enhance the overall efficiency of the economy, and allow lagging regions to benefit through economic specialization. Therefore, local governments should generally increase the intensity of environmental regulations and more vigorously regulate market failures, not only to improve environmental quality and labor productivity but also to promote market integration in China.

Third, we also noted that provinces with a higher degree of decentralization are better equipped to employ environmental regulation to promote domestic market integration. When local governments are granted more power, they can better fulfill their regulatory role and effectively compensate for market failures. However, fiscal decentralization is also an important cause of market fragmentation in China and has stimulated local protectionism (Lin and Liu 2000). Therefore, the central government should reform the existing fiscal decentralization model in favor of a more reasonable and scientific system and grant more economic and administrative powers to local governments. Further, the central government should also improve its GDP-based performance evaluation system for local governments by including more "soft indicators," such as environmental protection, social security, and citizen wellbeing.

Despite this study' contributions, there were some limitations in its analysis. First, although we noted that environmental regulations clearly facilitated market integration in China, our intertemporal decision-making model may not be applicable to extremely economically backward countries or have higher expected returns on capital. Second, while we discussed whether environmental regulations promote domestic market integration, we did not fully delve into the role of economic development level in this process due to model limitations. However, our results suggest that the level of economic development can indirectly affect market efficiency by influencing environmental welfare effects, which may ultimately affect regional economic specialization decisions. Therefore, the development of more refined models to overcome these limitations should be the focus of future research. 
Not applicable.

2. Consent to participate

We confirm that the manuscript has been read and approved by all named authors and that there are no other persons who satisfied the criteria for authorship but are not listed. We further confirm that the order of authors listed in the manuscript has been approved by all of us.

\section{Consent to publish}

The authors agree to publish this article in the Environmental Science and Pollution Research.

641

\section{Availability of data and materials}

The datasets used in this study are available from the corresponding author on reasonable request.

645

\section{Competing Interests}

647

The authors declare no competing interests

648

649

\section{Funding}

650

This work was supported by the National Natural Science Foundation of China [grant no. 71974001], the Major Research Projects of Natural Science in Universities of Anhui Province of China [grant no. KJ2017ZD35], and the Top Talent Project in Anhui Province [grant no. gxyqZD2020087].

\section{Authors' contributions}

Aolin Lai: Formal analysis, Investigation, Software, Writing - Original Draft; Zhihui Yang: Conceptualization, Writing - Review \& Editing, Supervision, Resources, Project administration, Editing.

660

\section{Acknowledgements}

662

We would like to thank Editage (www.editage.cn) for English-language editing.

663 


\section{References}

Ambec S, Cohen MA, Elgie S, Lanoie P (2013) The Porter hypothesis at 20: can environmental regulation enhance innovation and competitiveness? Review of environmental economics policy 7:2-22

Bator FM (1958) The Anatomy of Market Failure. The Quarterly Journal of Economics Vol.72:351-379 Berman E, Bui LTM (2001) Environmental regulation and productivity: Evidence from oil refineries. Rev. Econ. Stat. 83:498-510

Cai X, Zhu B, Zhang H, Li L, Xie M (2020) Can direct environmental regulation promote green technology innovation in heavily polluting industries? Evidence from Chinese listed companies. Science of The Total Environment 746:140810

Candau F, Dienesch E (2017) Pollution Haven and Corruption Paradise. Journal of Environmental Economics and Management 85:171-192

Chang IS, Wang W, Wu J, Sun Y, Hu R (2018) Environmental impact assessment follow-up for projects in China: Institution and practice. Environmental Impact Assessment Review 73:7-19

Chen X, Chang CP (2020) Fiscal decentralization, environmental regulation, and pollution: a spatial investigation. Environmental Science and Pollution Research 27:31946-31968

Clinch JP, Healy JD (2000) Domestic energy efficiency in Ireland: correcting market failure. Energy Policy 28:1-8

Costanza R, d'Arge R, de Groot R, Farber S, Grasso M, Hannon B, Limburg K, Naeem S, O'Neill RV, Paruelo J, Raskin RG, Sutton P, van den Belt M (1998) The value of ecosystem services: putting the issues in perspective. Ecological Economics 25:67-72

Cui L, Song M, Zhu L (2019) Economic evaluation of the trilateral FTA among China, Japan, and South Korea with big data analytics. Computers \& Industrial Engineering 128:1040-1051

Duan HB, Zhang GP, Wang SY, Fan Y (2019) Robust climate change research: a review on multi-model analysis. Environ. Res. Lett. 14:23

Fan F, Lian H, Liu X, Wang X (2020) Can environmental regulation promote urban green innovation Efficiency? An empirical study based on Chinese cities. J. Clean Prod.:125060

Fan X, Song D, Zhao X (2017) Does Infrastructure Construction Break up Domestic Market Segmentation? Economic Research Journal 52:20-34 (in Chinese)

Fan Z, Zhang J (2010) Fiscal Decentralization, Intergovernmental Transfer and Market Integration. Economic Research Journal 45:53-64 (in Chinese)

Givens JE, Jorgenson AK (2011) The Effects of Affluence, Economic Development, and Environmental Degradation on Environmental Concern: A Multilevel Analysis. Organ. Environ. 24:74-91

Gui Q, Chen M, Lu M, Chen Z (2006) China's domestic market tends to divide or consolidate: An analysis based on the relative prices. Journal of World Economy 2:20-30

$\mathrm{Hu}$ W, Wang D (2020) How does environmental regulation influence China's carbon productivity? An empirical analysis based on the spatial spillover effect. J. Clean Prod. 257:120484

Izquierdo SS, Izquierdo LR (2007) The impact of quality uncertainty without asymmetric information on market efficiency. Journal of Business Research 60:858-867

Jin F, Lee K, Kim YK (2008) Changing engines of growth in China: From exports, FDI and marketization to innovation and exports. China World Econ. 16:31-49

Ke S (2015) Domestic Market Integration and Regional Economic Growth—China's Recent Experience from 1995-2011. World Development 66:588-597

Lai A, Yang Z, Cui L (2021) Market segmentation impact on industrial transformation: Evidence for environmental protection in China. J. Clean Prod.:126607 
Lee M (2006) Environmental economics: A market failure approach to the commerce clause. Yale Law

$$
\text { J. 116:456-492 }
$$

Li H, Lu J (2020) Can regional integration control transboundary water pollution? A test from the Yangtze River economic belt. Environmental Science and Pollution Research 27:28288-28305

Li J, Qiu LD, Sun Q (2003) Interregional protection: Implications of fiscal decentralization and trade liberalization. China Econ. Rev. 14:227-245

Li J, Du Y (2020) Spatial effect of Environmental Regulation on Green Innovation EfficiencyEvidence from Prefectural-level Cities in China. J. Clean Prod.:125032

Li M, Du W, Tang S (2021) Assessing the impact of environmental regulation and environmental cogovernance on pollution transfer: Micro-evidence from China. Environmental Impact Assessment Review 86:106467

Li WH, Gu Y, Liu F, Li C (2019) The effect of command-and-control regulation on environmental technological innovation in China: a spatial econometric approach. Environmental Science and Pollution Research 26:34789-34800

Lin JY, Liu Z (2000) Fiscal decentralization and economic growth in China. Economic development and cultural change 49:1-21

Lu M, Chen Z, Yan J (2004) Increasing Return,Development Strategy and Regional Economic Segmentation. Economic Research Journal:54-63 (in Chinese)

Lu M, Chen Z (2009) Fragmented Growth:Why Economic Opening May Worsen Domestic Market Segmentation? Economic Research Journal 44:42-52 (in Chinese)

Mao YM (2018) Decentralization, national context and environmental policy performance: a fuzzy set qualitative comparative analysis. Environmental Science and Pollution Research 25:28471-28488

NBSC (2005-2018a) China Statistical Yearbook on Environment. China Statistics Press, Beijing.

NBSC (2005-2018b) China Statistical Yearbook. China Statistics Press, Beijing.

Parsley DC, Wei SJ (1996) Convergence to the law of one price without trade barriers or currency fluctuations. Q. J. Econ. 111:1211-1236

Peng X (2020) Strategic interaction of environmental regulation and green productivity growth in China: Green innovation or pollution refuge? Science of The Total Environment 732:139200

Poncet S (2003) Measuring Chinese domestic and international integration. China Econ. Rev. 14:1-21

Reinhardt F (1999) Market Failure and the Environmental Policies of Firms: Economic Rationales for "Beyond Compliance" Behavior. Journal of Industrial Ecology Vol.3:9-21

Shao Q, Wang X, Zhou Q, Balogh L (2019a) Pollution haven hypothesis revisited: A comparison of the BRICS and MINT countries based on VECM approach. J. Clean Prod. 227:724-738

Shao S, Chen Y, Li K, Yang L (2019b) Market segmentation and urban CO2 emissions in China: Evidence from the Yangtze River Delta region. Journal of Environmental Management 248:109324

Song KY, Bian YC, Zhu C, Nan YQ (2020) Impacts of dual decentralization on green total factor productivity: evidence from China's economic transition. Environmental Science and Pollution Research 27:14070-14084

Song Y, Yang TT, Zhang M (2019) Research on the impact of environmental regulation on enterprise technology innovation-an empirical analysis based on Chinese provincial panel data. Environmental Science and Pollution Research 26:21835-21848

Stern DI (2004) The Rise and Fall of the Environmental Kuznets Curve. World Development 32:14191439

Sun XX, Loh L, Chen ZW (2020) Effect of market fragmentation on ecological efficiency: evidence from 
environmental pollution in China. Environmental Science and Pollution Research 27:4944-4957

Testa F, Iraldo F, Frey M (2011) The effect of environmental regulation on firms' competitive performance: The case of the building \& construction sector in some EU regions. Journal of Environmental Management 92:2136-2144

Treisman D (2006) Fiscal decentralization, governance, and economic performance: a reconsideration. Economics \& Politics 18:219-235

Wang B, Wu Y, Yan P (2010) Environmental Efficiency and Environmental Total Factor Productivity Growth in China's Regional Economies. Economic Research Journal 45:95-109 (in Chinese)

Welsch H (2007) Environmental welfare analysis: A life satisfaction approach. Ecological Economics 62:544-551

Wu H, Xu L, Ren S, Hao Y, Yan G (2020) How do energy consumption and environmental regulation affect carbon emissions in China? New evidence from a dynamic threshold panel model. Resources Policy 67:101678

Xiwei Z, Jin X, Luo D (2005) Market Segmentation and the Expansion of China's Export. Economic Research Journal 12:68-76 (in Chinese)

Young A (2000) The razor's edge: Distortions and incremental reform in the People's Republic of China. Q. J. Econ. 115:1091-1135

Zhang C, Lu Y, Guo L, Yu T (2011) The Intensity of Environmental Regulation and Technological Progress of Production. Economic Research Journal 2:3-124 (in Chinese)

Zhang H, Zhu Z, Fan Y (2018) The impact of environmental regulation on the coordinated development of environment and economy in China. Natural Hazards 91:473-489

Zhang K, Shao S, Fan S (2020) Market integration and environmental quality: Evidence from the Yangtze river delta region of China. Journal of Environmental Management 261:110208

Zhou Q, Song Y, Wan N, Zhang X (2020) Non-linear effects of environmental regulation and innovation - Spatial interaction evidence from the Yangtze River Delta in China. Environmental Science \& Policy 114:263-274

Zhu Y, Liang DP, Liu TS, Song YZ (2020) The impact of production factor distortion on total factor energy productivity: insight from China's region level. Environmental Science and Pollution Research 27:40715-40731 
Figures

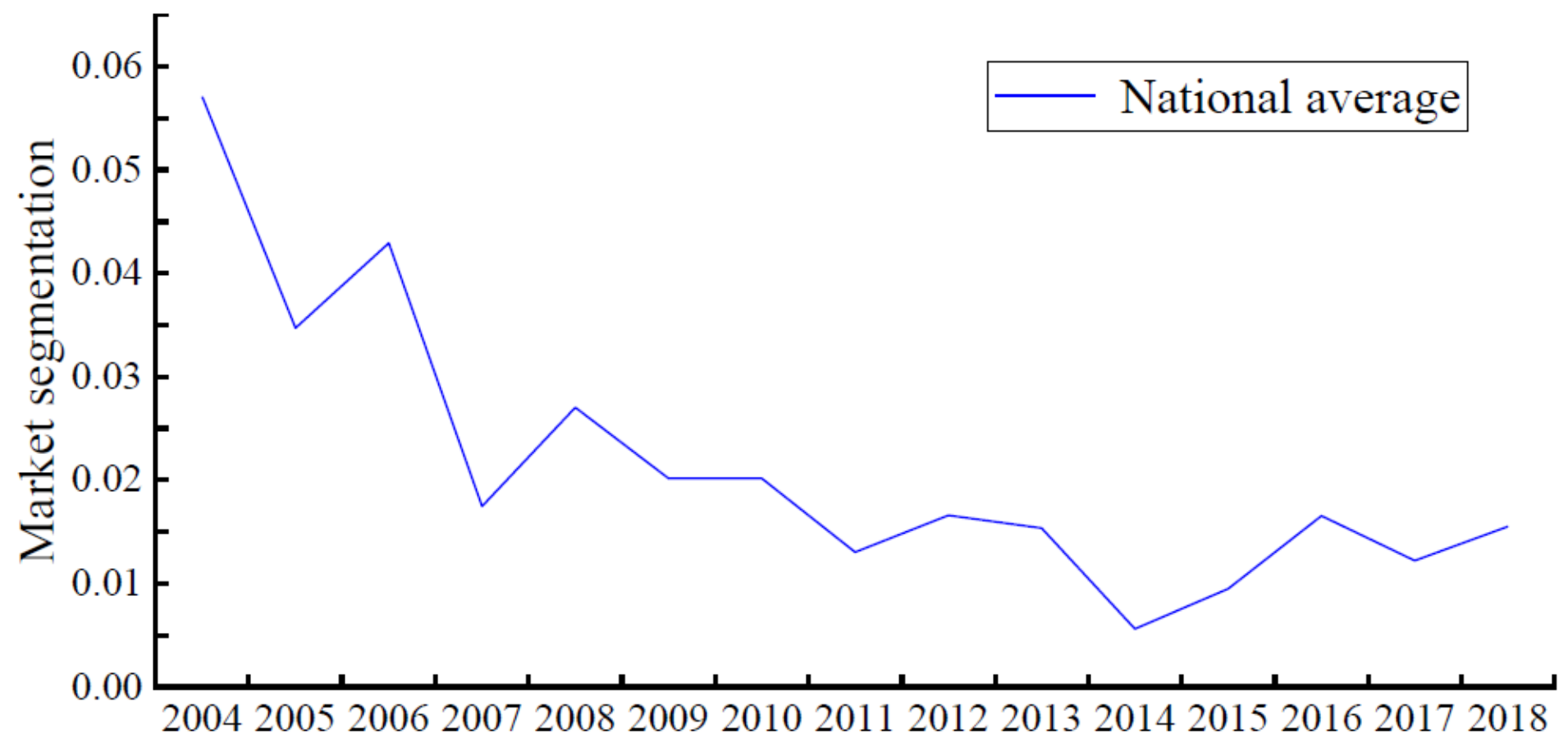

Figure 1

Market segmentation trends in China

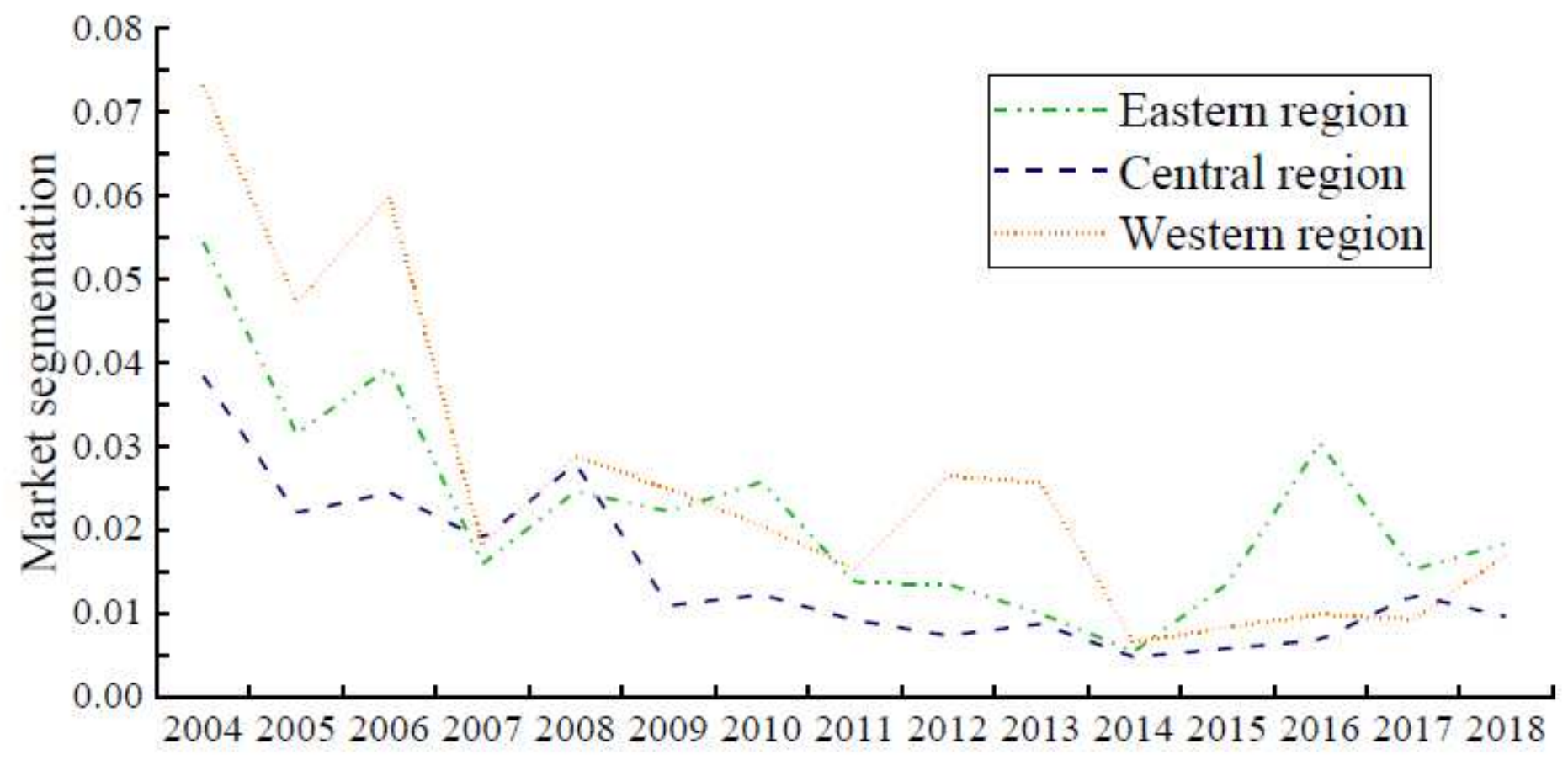

Figure 2 


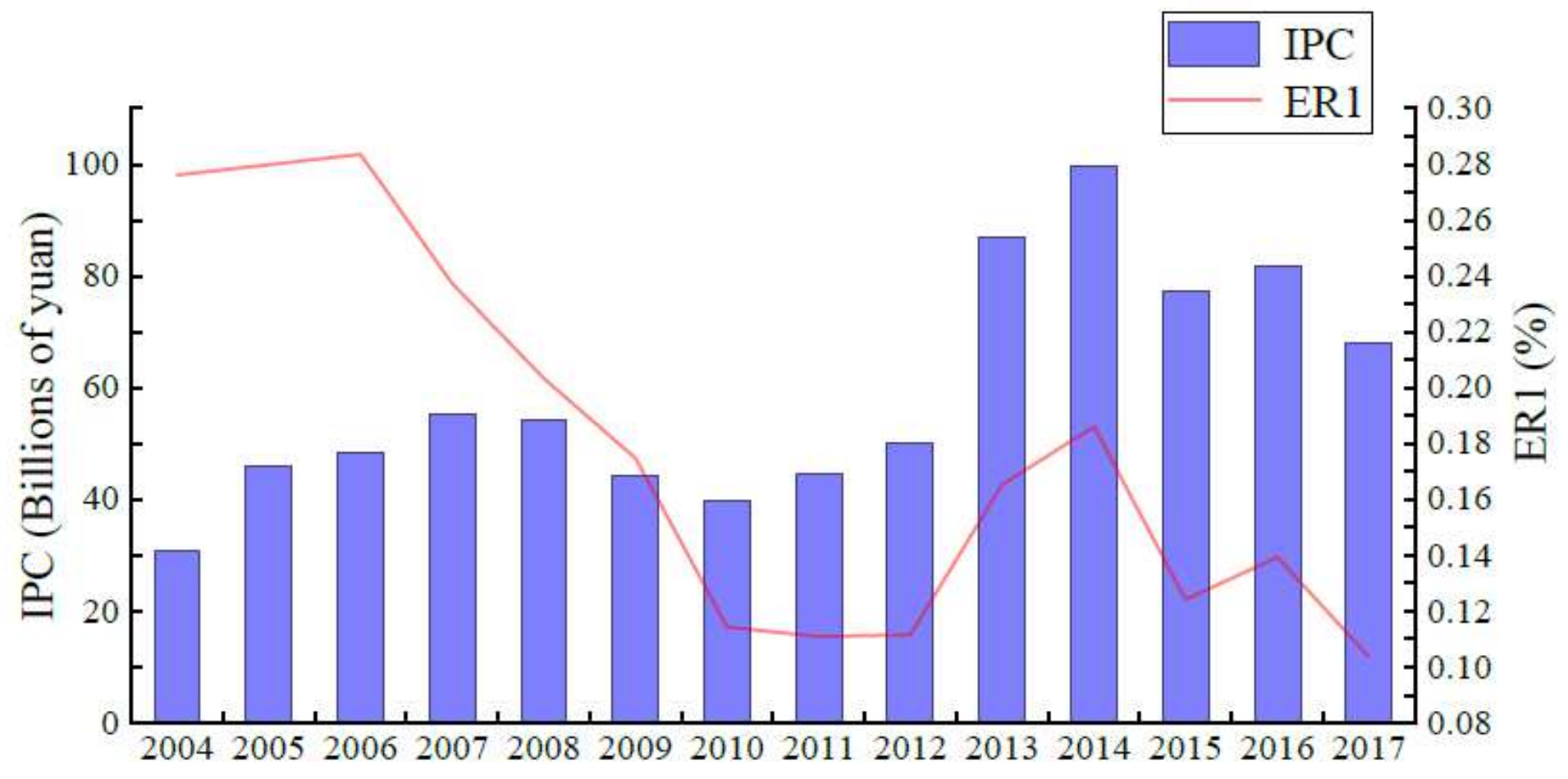

Figure 3

Trend of environmental regulatory intensity in China. IPC: investment in industrial pollution control

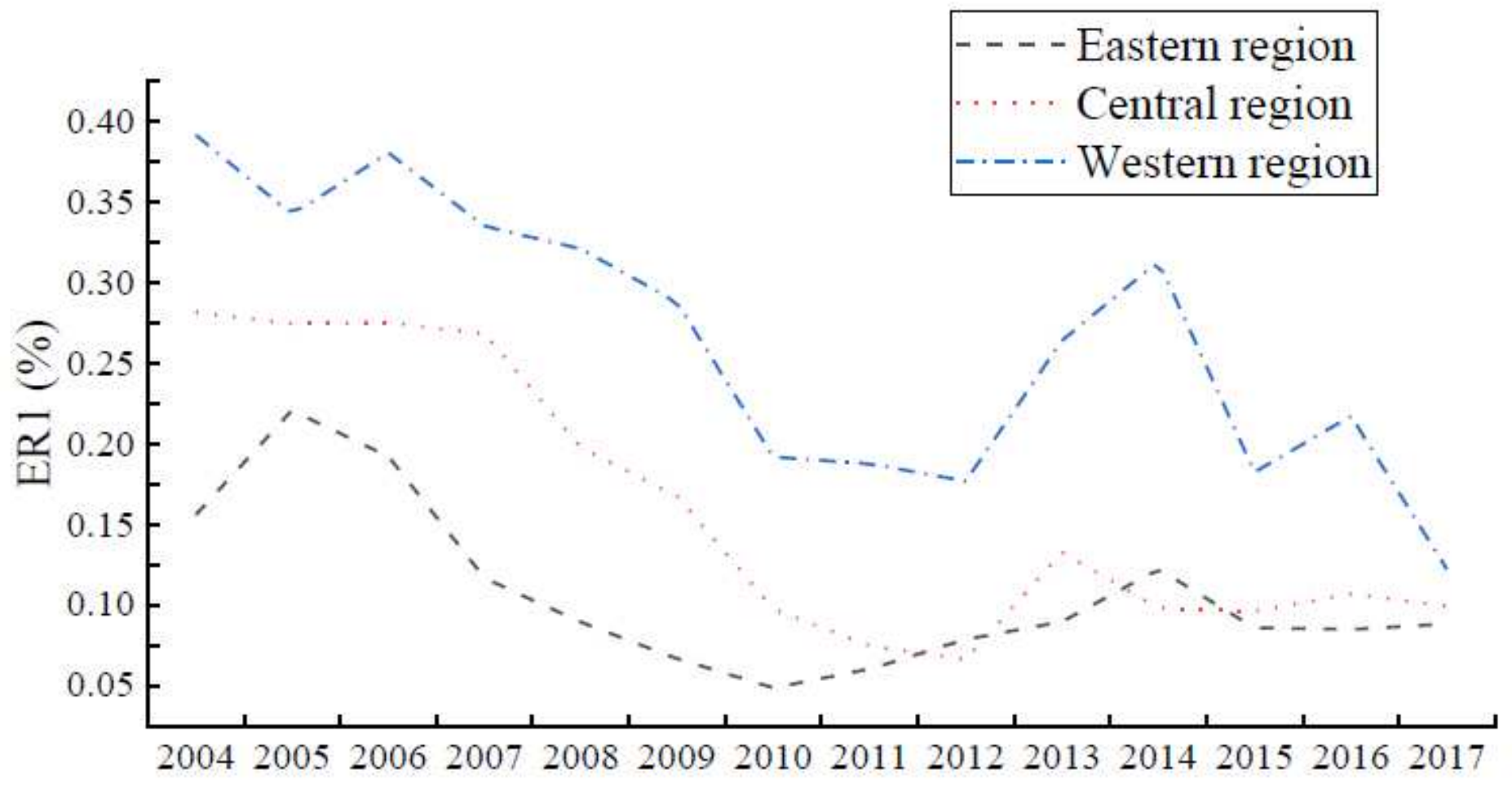

Figure 4 
Changes in environmental regulatory intensity by region
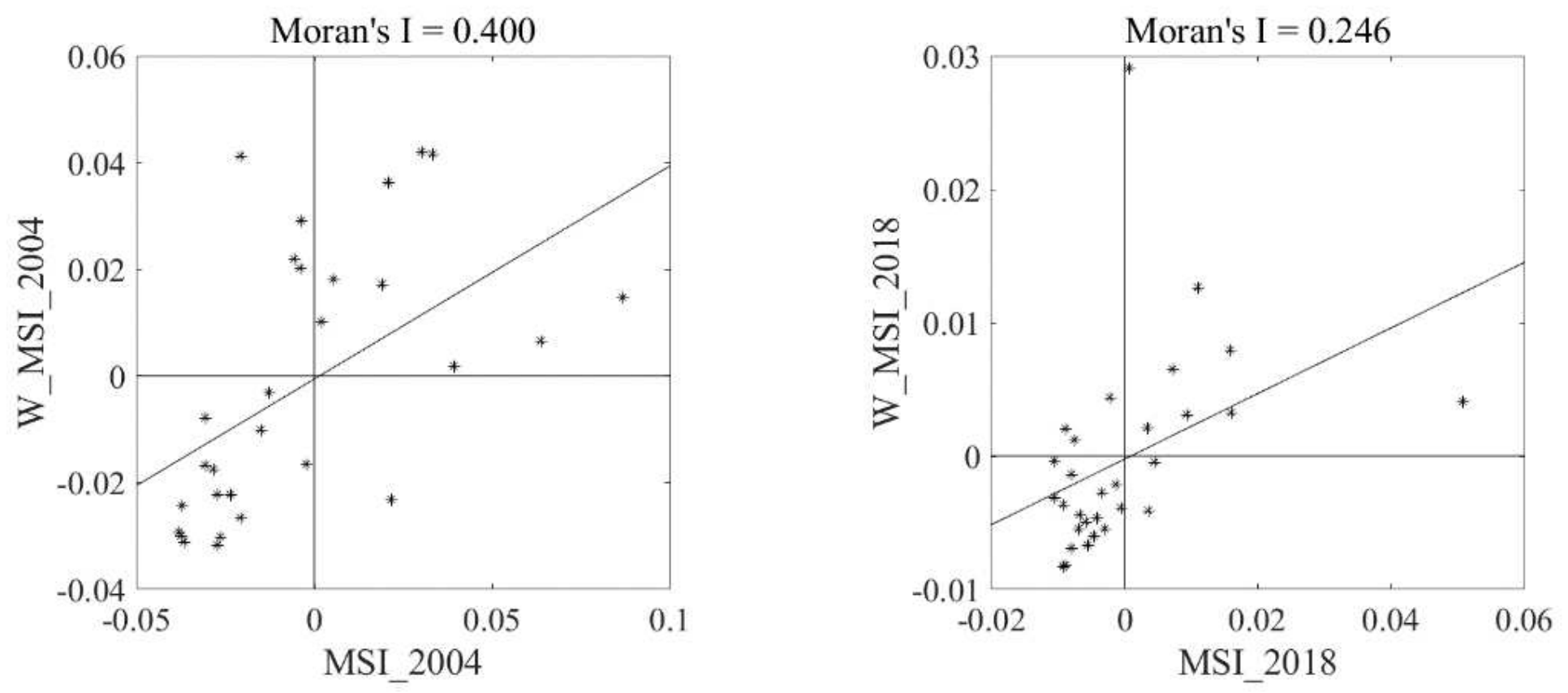

Figure 5

Scatterplot of Moran's I index (怄区) for provincial market segmentation in China in 2004 and 2018 